\title{
A AVALIAÇÃO POR PARES ${ }^{1}$
}

Os avanços da ciência brasileira, a partir do início dos anos 50, quando foram criados o Conselho Nacional de Pesquisas (CNPq) e a Campanha de Aperfeiçoamento de Pessoal de Nível Superior (CAPES), são inquestionáveis e visíveis sem necessidade de lentes de aumento.

A implantação, no CNPq, dos Comitês Assessores (CAs) e, na CAPES, das Coordenações de Áreas, com o objetivo de avaliar o pesquisador e os cursos de pós-graduação, respectivamente, foram decisivos para alçar o Brasil ao seleto grupo das 20 nações com maior produção científica no mundo. Graças ao sistema de avaliação da CAPES, os melhores Programas de Pós-Graduação na área de Química são de qualidade comparável ao de muitos países industrializados. Não é demais relembrar que o setor acadêmico forma, atualmente, 300 doutores e é responsável por mais de $90 \%$ das publicações no exterior, a despeito do Brasil ter duas revistas - Química Nova (http:// quimicanova.sbq.org.br/quimicanova.htm), FI = 0,627 e o Journal of the Brazilian Chemical Society (http://jbcs.sbq.org.br), FI = 1,161, esta última a de maior impacto entre todas as revistas científicas latinoamericanas da área de ciências exatas ${ }^{2-4}$. Se a Química acadêmica brasileira está, neste momento, além da fronteira de publicações de artigos científicos e da formação de doutores, está aquém da transformação da indústria química brasileira em uma indústria de especialidades, bem como da transformação do conhecimento em riqueza para a nação.

O sistema de avaliação por pares ${ }^{1}$, "peer review”, deve ser pautado no mérito acadêmico-científico-tecnológico do pesquisador ou do curso e utilizar critérios qualitativos, admitindo-se, no entanto, que subsidiariamente se utilizem critérios quantitativos. Os critérios precisam ser amplamente conhecidos (e legitimados), as mudanças requerem amplo debate e a construção de consensos. Na avaliação por pares, necessariamente, os critérios pertencem à comunidade avaliada e não aos avaliadores, caso contrário, a avaliação não seria realizada por "pares"!

O que se observa atualmente é uma crescente onda de insatisfação dos avaliados (pesquisadores e cursos) com os critérios e parâmetros da avaliação que, muitas vezes, ou não estão bem qualificados, ou utilizam parâmetros puramente quantitativos que negam o princípio da avaliação por pares. Isso sinaliza um futuro incerto, sem Comitês de Avaliação, onde uma planilha e um programa de computador poderão gerar um ranking como, por exemplo, no caso dos jogadores de tênis!

A partir dos anos 90, alguns bioquímicos brasileiros começaram a propor a introdução do parâmetro Fator de Impacto $^{2}$ dos periódicos científicos e o número de citações para avaliação dos pesquisadores. $\mathrm{O}$ que era uma simples proposta ganhou projeção e virou uma verdadeira febre, apesar do parâmetro fator de impacto vir sendo abandonado pelas agências e universidades dos países desenvolvidos.

A utilização do FI nos sistemas de avaliação de departamentos, universidades e agências de fomento ganhou mais importância do que merece. Isso não significa que não deva ser usado nas avaliações. A comunidade química brasileira orgulha-se do fator de impacto das revistas da Sociedade Brasileira de Química ${ }^{3,4}$. Estes números foram perseguidos com muita tenacidade durante cinco anos. Hoje, entretanto, observa-se uma tendência nos processos de avaliação em contar "papers" e ponderá-los com o fator de impacto do periódico onde foram publicados. A exacerbação da quantificação nas avaliações resguarda mais os avaliadores que os avaliados, especialmente quando o resultado do processo de avaliação é o financiamento, a concessão de bolsas de produtividade de pesquisa ou o conceito de um programa de pós-graduação. O reconhecimento de mérito é mais complexo e requer excelência tanto dos avaliados quanto dos avaliadores, não pode se limitar a um ou dois indicadores.

Uma das questões principais envolvidas na avaliação é a caracterização do "mérito" e do "impacto". A avaliação do mérito, necessariamente é qualitativa e a avaliação do impacto envolve critérios quantitativos. Como considerar o mérito e o impacto? Certamente, isto só poderá ser feito por "pares" que consigam perceber e reconhecer o mérito acadêmico-científico-tecnológico, bem como identificar parâmetros que permitam medir o impacto. Por exemplo, um pesquisador cujo trabalho tenha mérito e impacto relevantes, necessariamente não os transfere automaticamente para o curso no qual é docente! O inverso também é verdadeiro. A avaliação do pesquisador envolve o seu desempenho acadêmico-cientificotecnológico, enquanto que a avaliação de cursos de pós-graduação precisa considerar o desempenho dos seus professores e estudantes, os impactos regional, nacional e internacional do coletivo, bem como o destino dos estudantes.

Não compete aqui definir qual(is) o(s) melhor(es) ou pior(es) critérios para avaliação, mas sim convidar a comunidade de Química para a reflexão e um amplo debate sobre avaliação pelos pares. Com esse objetivo, os leitores são convidados a escrever para o endereço editor@jbcs.sbq.org.br de forma a contribuir para o aprimoramento do sistema de avaliação por pares, no qual o mérito, o impacto da publicação, a formação acadêmica e a transformação do conhecimento em riqueza coexistam de forma harmônica.

Para melhor balizamento dessa discussão, são feitas as seguintes perguntas:

i) é possível diferenciar os critérios de avaliação de pesquisadores dos de cursos de pós-graduação, sem prejuízos para ambos?

ii) é possível qualificar (e medir) a contribuição intelectual de diferentes autores de um mesmo trabalho cientifico e distinguí-las da contribuição técnica e/ou instrumental?

iii) como comparar artigos pouco citados, publicados em periódicos de alto fator de impacto com artigos muito citados publicados em periódicos de baixo ou médio fator de impacto?

iv) como apropriar a produção cientifica e tecnológica dos docentes na avaliação de cursos de pós-graduação?

v) como valorizar o impacto do conhecimento gerado nos programas de pós-graduação e a importância dos egressos destes programas no desenvolvimento das atividades de ciência e de tecnologia no país?

Jailson B. de Andrade (Editor J. Braz. Chem. Soc.)

\section{REFERÊNCIAS}

1. de Andrade, J. B.; J. Braz. Chem. Soc. 2005, 16, 891-Editorial

2. Pinto, A. C.; de Andrade, J. B.; Quim. Nova 1999, 22, 448.

3. Pinto, A. C.; de Andrade, J. B.; J. Braz. Chem. Soc. 2005, 16, 683Editorial.

4. Córdoba de Torresi, S. I.; Pardini, V. L.; Ferreira, V. F.; Pinto, A. C.; de Andrade, J. B.; Quim. Nova 2005, 28, 745-Editorial. 